disturbances in calcium metabolism nor do we have proof of impaired mucopolysaccharide metabolism to provide some aetiological clues for the basal ganglia calcification. Thus, we must await a more definitive explanation before drawing any conclusions regarding the pathogenesis of basal ganglia calcification in Down's syndrome.

1 Wisniewski KE, French JH, Rosen JF, Koslowski PB, Tenner M, Wisniewski HM. Basal ganglia calcification (BGC) in Down's syndrome. Another manifestation of premature aging. Ann NY Acad Sci 1982;396:179-89.

2 Jakab I. Basal ganglia calcification and psychosis in mongolism. Eur Neurol 1978;17:300-14.

3 Lowenthal A, De Deyn P. Striopallidodentate calcifications. In: Joseph AB, Young RR, eds. Movement disorders in neurolIn: Joseph AB, Young RR, eds. Movement disorders in neurol-
ogy and neuropsychiatry. Oxford: Blackwell Scientific Publiogy and neuropsychiatry.

\section{Final diagnosis}

Bilateral basal ganglia calcification in Down's syndrome.

Keywords: Down's syndrome; calcification; basa ganglia

\footnotetext{
4 Benda CE. The child with mongolism (congenital acromicria). New York: Grune \& Stratton, 1960.

5 Murofushi K. Symmetrischer Pseudokalk in stammganglien and Grosshirnmark mit diskreter Leukencephalopathie bei Downschem syndrom. Neuropediatrie 1974;5 103-8.
}

Poole Hospital NHS

Trust,

Longfleet Road,

Poole,

Dorset BH15 2JB, UK

S Zaman

M Thomas

The Royal

Bournemouth

Hospital,

Castle Lane East,

Bournemouth,

Dorset BH7 7DW, UK

J Mallya

Correspondence to

Dr M Thomas

Accepted 25 June 1997

\section{A man with purple toes}

\author{
Syed Zaman, Jagadish Mallya, Matthew Thomas
}

A 79-year-old man was admitted for urgent angiography because of pain and discolouration of his toes. Six months prior to admission he was commenced on amiodarone and warfarin for paroxysmal atrial fibrillation. He was known to have hypercholesterolaemia, ischaemic heart disease and congestive cardiac failure. He was an ex-smoker. His other medications were enalapril, frusemide and cholestyramine.

Examination revealed purple discolouration of his toes with evidence of digital infarction (figures 1 and 2), blood pressure was $140 / 80 \mathrm{mmHg}$ and no murmurs or bruits were audible. Lower limb pulses were all palpable and Doppler pressure studies suggested small vessel occlusion without significant large vessel disease.

Investigations revealed: haemoglobin $12.2 \mathrm{~g} / \mathrm{dl}$, platelets $337 \times 10^{9} / 1$, erythrocyte sedimentation rate (ESR) $36 \mathrm{~mm} / \mathrm{h}$, white blood cells $6.9 \times 10^{9} / 1$ (neutrophils 4.5 , lymphocytes 1.5 , monocytes 0.5 , eosinophils 0.1 , basophils 0.1 ). Na $141 \mathrm{mmol} / 1, \mathrm{~K} 4.7 \mathrm{mmol} / 1$, urea $12.1 \mathrm{mmol} / 1$ creatinine $169 \mathrm{mmol} / 1$, cholesterol $3.6 \mathrm{mmol} / 1$, auto-immune profile and ANCA negative. Electrocardiogram showed sinus rhythm, left ventricular hypertrophy, anteroseptal $Q$ waves. Echocardiography showed impaired left ventricular function. Abdominal ultrasound showed a 4-cm abdominal aortic aneurysm.

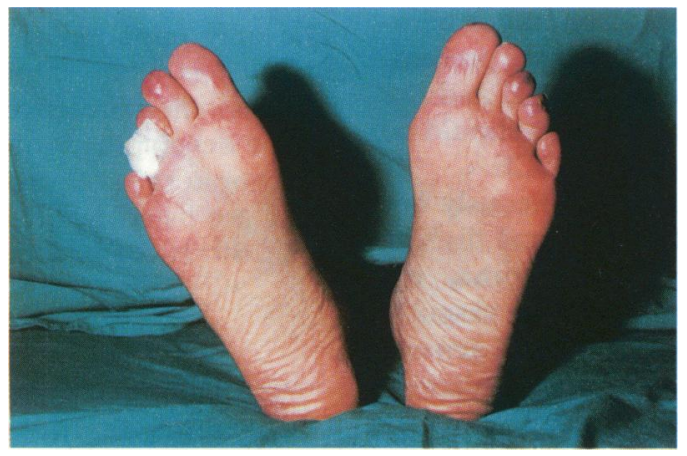

Figure 1

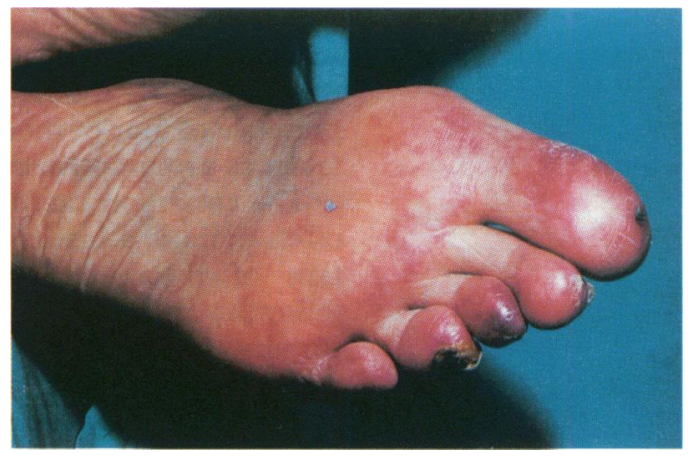

Figure 2

\section{Questions}

1 Give the most probable diagnosis and list the risk factors for the condition.

2 List five other clinical manifestations of this disorder.

3 Comment on management and prognosis. 
Answers

QUESTION 1

Cholesterol crystal embolism (CCE). The risk factors for CCE are listed in box 1.

\section{Risk factors for CCE}

- atherosclerotic cardiovascular disease

- hypertension

- angiography/angioplasty

- anticoagulant/thrombolytic therapy

- vascular surgery

- male sex

- age greater than 50 years

- smoking history

- hypercholesterolaemia

- diabetes mellitus

- cardiopulmonary resuscitation

Box 1

The presence of pedal pulses with digital infarction suggests small vessel disease. CCE is a well-recognised but probably underdiagnosed disorder where cholesterol crystals embolise from atherosclerotic plaques, occluding arterioles with an external diameter ranging from 55 to $900 \mu \mathrm{m}$, thus causing irreversible organ dysfunction.

The reported incidence of CCE is variable; in a recent study of the Dutch population CCE was reported with an average frequency of 6.2 cases per million population per year. ${ }^{1}$ Mayo and Swartz, in their review of in-patient nephrology consultations, suggest an incidence of at least one case every two weeks. ${ }^{2}$ Both papers suggest that the condition is probably underdiagnosed.

The typical patient with CCE is elderly, male and has a history of hypertension and atherosclerotic disease. The more risk factors present, the more likely the diagnosis of CCE and the presence of four or more risk factors should be taken as presumptive evidence of CCE. ${ }^{2}$

The condition can occur spontaneously but often there is a history of mechanical disruption of thrombus overlying atheroma, eg, following angiography, angioplasty or vascular surgery, thus exposing the plaque to the general circulation. Thrombolysis and anticoagulation, by destabilising atheromatous plaques, are recognised precipitants and with the increasing use of these drugs clinicians should exercise vigilance for the development of CCE.

QUESTION 2

Many organs can be affected (box 2) thus the clinical features (box 3) depend on the site(s) of embolisation. The commonest clinical presentations are cutaneous features, renal failure (50\% of cases) and accelerated hypertension. Nonspecific presentation can occur with fever, myalgia or weight loss and can be confused

\begin{tabular}{|ll|}
\hline $\begin{array}{l}\text { Organ involvement in CCE } \\
\text { (\% occurrence) }\end{array}$ & \\
\hline - kidney & \\
\hline - spleen & $(73)$ \\
- bowel & $(42)$ \\
- pancreas & $(28)$ \\
- skin/muscle & $(20)$ \\
- adrenal & $(19)$ \\
- heart & $(12)$ \\
- brain & $(12)$ \\
- liver & $(12)$ \\
\hline
\end{tabular}

Box 2

Clinical features of CCE
- fever
- myalgia
- weight loss
- lower extremity pain
- gastrointestinal bleeding
- cutaneous manifestations: livedo reticularis,
purpura, cyanosis, 'purple toes', cutaneous
- necrosis
- Hollenhorst plaques
- vascular bruits
- encephalopathy/altered mental state
- renal impairment
- pancreatitis

Box 3

with other systemic disorders such as infective endocarditis and vasculitis.

Cutaneous features occur in up to $35 \%$ of patients and tend to be bilateral. Our patient presented with 'purple toes', a complication particularly associated with warfarin therapy. ${ }^{3}$ The only opportunity to visualise cholesterol emboli is on fundoscopy (Hollenhorst plaques); their presence is an important marker for the development of cerebral infarction. ${ }^{4}$

Laboratory abnormalities associated with CCE are listed in box 4. Eosinophilia occurs often, $39-100 \%$ in some series. ${ }^{4}$

\section{Laboratory features of CCE}

- ESR greater than $30 \mathrm{~mm} / \mathrm{h}$

- eosinophilia/eosinophiluria

- thrombocytopenia

- raised amylase

- elevated creatine kinase

- abnormal liver function tests

- elevated serum urea and creatinine

- hypocomplementaemia 
QUESTION 3

If at all possible, the diagnosis should be confirmed histologically by tissue biopsy of skin or kidney to reveal the pathognomonic needle-shaped clefts in arterioles. Once established, invasive procedures known to precipitate CCE should be avoided. Anticoagulation and thrombolysis are also contraindicated. Associated risk factors such as hypertension, hypercholesterolaemia and smoking should be managed aggressively. Renal replacement therapy may be required.

Once pre-mortem diagnosis is made (less than $40 \%$ of cases) prognosis is poor. Mortality is high, with death most commonly due to ischaemic heart disease, cerebrovascular disease and renal failure, while $10.8 \%$ of patients die of the multiple cholesterol emboli syndrome.

Heightened awareness of CCE will lead to early diagnosis, thus avoiding precipitating factors. Unnecessary immunosuppressant therapy will also be avoided since CCE can mimic the clinical presentation of systemic vasculitis. ${ }^{5}$

Our patient did not undergo angiography, nor tissue biopsy and his condition deteriorated rapidly despite stopping warfarin. There was progressive renal failure and a step-wise

1 Moolenar W, Lamers CBHW. Cholesterol crystal embolism in the Netherlands. Arch Intern Med 1996;156:653-7.

Mayo RR, Swartz RD. Redefining the incidence of clinically detectable atheroembolism. Am ₹ Med 1996;100:524-9.

3 Falanga F, Fine MJ, Kapoor WN. The cutaneous manifestaFalanga F, Fine MJ, Kapoor WN. The cutaneous manifesta-
tions of cholesterol crystal embolism. Arch Dermatol 1986; 122:1194-8.

\section{Learning points}

- clinicians should have a heightened awareness of CCE

- CCE may mimic other systemic diseases eg vasculitis

- once diagnosed, precipitating factors should be avoided

Box 5

decline in cognitive function secondary to vascular dementia (brain computed tomography scan revealed multiple small ischaemic areas). He died four months after presentation. The presence of more than four risk factors together with the clinical features makes the diagnosis of CCE very likely.

\section{Final diagnosis}

Cholesterol crystal embolism.

Keywords: cholesterol crystal embolism; purple toes; renal failure; anticoagulation

\footnotetext{
4 Robson MG, Scoble JE. Atheroembolic disease. $\mathrm{Br} \mathcal{F}$ Hosp Med 1996;55:648-52.

5 Peat DS, Mathieson PW. Cholesterol emboli may mimic
} systemic vasculitis. BMF 1996;313:546-7.
Department of Surgery, Gwynedd

Hospital, Bangor, Gwynedd LL57 2PW, UK

D S Bhandarkar

T R Raju

L R Jenkinson

Correspondence to $\mathrm{Mr} \mathrm{L} \mathrm{R}$ Jenkinson

Accepted 28 May 1997

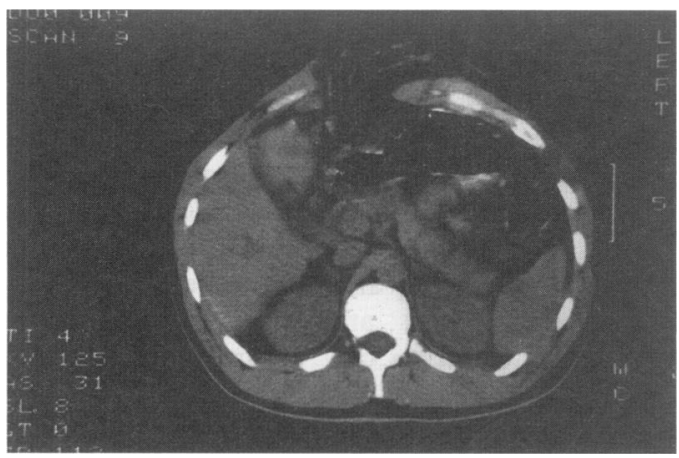

\section{Questions}

1 What is the diagnosis?

2 What is the differential diagnosis of an abdominal wall swelling appearing after blunt trauma? 